\title{
Survey for toxigenic Fusarium species on maize kernels in China
}

\author{
P.W. Qin ${ }^{1}$, J. Xu², Y. Jiang ${ }^{2}$, L. Hu${ }^{2}$, T. van der Lee ${ }^{3}$, C. Waalwijk ${ }^{3}$, W.M. Zhang ${ }^{4}$ and X.D. $\mathrm{Xu}^{2 *}$ \\ ${ }^{1}$ College of Plant Protection, Shenyang Agricultural University, Shenhe Street, Dongling Road No.120, Shenyang, 110161, \\ China P.R.; ${ }^{2}$ Plant Protection Institute, Liaoning Academy of Agricultural Sciences, Shenyang, 110161, China P.R.; ${ }^{3}$ Plant \\ Research International, Business Unit Biointeractions, P.O. Box 16, 6700 AA Wageningen, the Netherlands; ${ }^{4}$ Plant Protection \\ Station of Liaoning Province, Shenyang 110034, China P.R.; xiudex@163.com
}

Received: 29 August 2019 / Accepted: 13 December 2019

( 2020 Wageningen Academic Publishers

OPEN ACCESS CC) (1) () RESEARCH ARTICLE

\begin{abstract}
Maize is currently the most important crop in China. A major concern in maize production is maize ear rot caused by Fusarium spp., which results in yield losses, reduction of seed quality and the accumulation of mycotoxins in the harvested grains. To identify the importance of the different Fusarium species in maize infection, we performed a comprehensive survey on 9,000 asymptomatic and randomly collected maize kernels. Seeds were collected from 12 different provinces covering all major maize growing areas in China and included five maize varieties. In total 1,022 Fusarium isolates were retrieved that were identified based on morphological characteristics, by species specific diagnostic PCRs and by EF1- $\alpha$ gene sequencing. Eight different species were identified: Fusarium verticillioides (75.34\%), Fusarium graminearum (8.32\%), Fusarium proliferatum (7.14\%), Fusarium subglutinans (4.11\%), Fusarium meridionale (1.57\%), Fusarium oxysporum (1.37\%), Fusarium semitectum (1.17\%), and Fusarium asiaticum (0.98\%). The distribution of Fusarium species was found to be different in different regions with the largest diversity observed in Hubei province, where all eight Fusarium species were isolated. Genetic chemotyping within the F. graminearum species complex indicated that all of the $85 \mathrm{~F}$. graminearum isolates showed the 15-acetyldeoxynivalenol chemotype, whereas all F. asiaticum $(\mathrm{n}=10)$ and $F$. meridionale $(\mathrm{n}=16)$ isolates had the nivalenol chemotype even when isolated from the same maize field. To our knowledge this is the largest collection of Fusarium isolates from maize and further exploitations of this collection are discussed.
\end{abstract}

Keywords: maize ear rot, Fusarium spp., population structure, mycotoxin chemotype

\section{Introduction}

Maize is one of the principal crops grown for human food, industrial usage and livestock feed in China. Its yield and quality can be affected by many kinds of fungi and it is one of the crops subject to the most critical mycotoxin problems throughout the world. Although many toxic fungal metabolites can be found in maize (Gao et al., 2005), management has focused on a few mycotoxins that occur with greater frequency or are associated with particularly undesirable consequences. These include deoxynivalenol (DON, a trichothecene mycotoxin, produced primarily by Fusarium graminearum and Fusarium culmorum), zearalenone (ZEN), an estrogenic compound produced primarily by $F$. graminearum and fumonisins (produced primarily by Fusarium verticillioides and Fusarium proliferatum). Each of these toxins is associated with a specific set of health detriments that have been documented in domestic animals and either documented or suspected for humans (CAST, 2003). Fusarium Ear Rot (FER) in maize can be caused by a wide range of fungal pathogens, with $F$. verticillioides and $F$. graminearum being the most important ear-rotting pathogens of maize in many areas of China (Bai, 1997; Xu and Liu, 2009). FER reduces both the yield as well as the grain quality due to the accumulation of mycotoxins produced by these Fusarium pathogens. This is of considerable concern to livestock producers and to human health. Besides causing direct and indirect economic losses, these fungi can also affect the health of grain handlers and processors. 
As the incidence and severity of FER is subject to climate and locations as well as agronomic measures and the maize variety, monitoring is important to assess risks and trends. This can guide adequate control and protection measures, that include proper grain drying, storage of grain at low moisture levels, and sanitation of feed preparation and delivery systems. Cultural practices designed to reduce mycotoxin contamination of crops should be based on plant disease epidemiology (reviewed by Munkvold, 2003). In many parts of China, especially in rural areas, farmers produce maize primarily for home consumption and to feed their animals. After harvest, maize is commonly stored in sheds or in containers, such as homemade bins. Grain dries slowly in these bins, consequently the moisture content can remain high enough to allow continued growth of the fungi as well as toxin production by fungi that have infected the kernels preharvest. Insects may continue to feed on maize in the field late in the season, enhancing the ability of fungi to infect the kernels. The aims of this study were: (1) to establish a protocol for surveys in China and to start a collection of viable accessions for future reference; (2) to understand which species of Fusarium infect maize kernels and their frequencies in different provinces; and (3) to determine the toxigenic chemotypes of different Fusarium spp. The results provide an effective base level on the toxigenic genotype and toxin production capacity of major pathogenic Fusarium spp. causing maize kernel rot in China and provide an early warning platform for stakeholders in regional maize production.

\section{Materials and methods}

\section{Samples collection of maize kernels and Fusarium spp. isolation}

In 2016, five maize varieties (N28, Qi319, Huang Zaosi, Oh7, Lu Yuan 92) with different resistance levels to Fusarium ear rot (Xu et al., 2019), were planted in 12 provinces, including Heilongjiang, Jilin, Liaoning, Inner Mongolia, Hebei, Shandong, Shanxi, Hubei, Henan, Gansu, Guizhou and Sichuan Provinces (Table 1). Five cobs per variety were harvested at physiological maturity stage and transported to local research units in the provinces and kernels were removed from the cob after 1-2 weeks on air-drying at room temperature. Maize kernels from each variety were mixed together as one sample and five samples from each location were transported to the Institute of Plant Protection, Liaoning Academy of Agricultural Sciences (IPP-LAAS, Shenyang city). Subsequently, all samples $(5 \times 12)$ were analysed for the percentage of Fusarium species contaminating the maize kernels and pathogen chemotypes detection.

For isolation of Fusarium spp., a total of 150 maize kernels from each of the 60 samples were taken at random for testing. The kernels were washed with distilled water to
Table 1. Maize samples from different province or locations used for isolation of Fusarium species.

\begin{tabular}{|c|c|c|c|}
\hline $\begin{array}{l}\text { Province } \\
\text { of samples } \\
\text { taken }\end{array}$ & $\begin{array}{l}\text { Cities of } \\
\text { samples } \\
\text { taken }\end{array}$ & $\begin{array}{l}\text { GPS data of } \\
\text { collection sites }\end{array}$ & $\begin{array}{l}\text { No. of maize } \\
\text { kernels for } \\
\text { isolation of fung }\end{array}$ \\
\hline Helongjiang & Harbin & $\mathrm{N} 45^{\circ} 45, \mathrm{E} 126^{\circ} 41$ & 750 \\
\hline Jilin & Gongzhuling & $\mathrm{N} 43^{\circ} 50^{\prime}, \mathrm{E} 124^{\circ} 82^{\prime}$ & 750 \\
\hline Liaoning & Shenyang & $\mathrm{N} 41^{\circ} 50^{\prime}, \mathrm{E} 123^{\circ} 24^{\prime}$ & 750 \\
\hline Inner Mogolia & Chifeng & $\mathrm{N} 42^{\circ} 27, \mathrm{E} 118^{\circ} 92^{\prime}$ & 750 \\
\hline Hebei & Sijiazhuang & $\mathrm{N} 38^{\circ} 02, \mathrm{E} 114^{\circ} 30^{\prime}$ & 750 \\
\hline Shandong & Jinan & $\mathrm{N} 36^{\circ} 40, \mathrm{E} 117^{\circ} 00^{\prime}$ & 750 \\
\hline Shanxi & Fenyang & $\mathrm{N} 37^{\circ} 27, \mathrm{E} 111^{\circ} 75^{\prime}$ & 750 \\
\hline Henan & Zhengzhou & $\mathrm{N} 34^{\circ} 46, \mathrm{E} 113^{\circ} 40^{\prime}$ & 750 \\
\hline Hubei & Nanzhang & $\mathrm{N} 31^{\circ} 78, \mathrm{E} 111^{\circ} 83^{\prime}$ & 750 \\
\hline Gansu & Pingliang & $\mathrm{N} 35^{\circ} 55, \mathrm{E} 106^{\circ} 67^{\prime}$ & 750 \\
\hline Guizhou & Guiyang & $\mathrm{N} 26^{\circ} 35, \mathrm{E} 106^{\circ} 42^{\prime}$ & 750 \\
\hline Sichuan & Luzhou & $\mathrm{N} 28^{\circ} 54, \mathrm{E} 105^{\circ} 24^{\prime}$ & 750 \\
\hline Total & & & 9,000 \\
\hline
\end{tabular}

remove attached dirt or dust and put on sterilised filter papers to remove extra water. Subsequently, the kernels were surface sterilised in $2 \%$ sodium hypochlorite solution for $5 \mathrm{~min}$, rinsed in three changes of sterile distilled water and placed on potato dextrose agar (PDA) medium at a density of ten kernels per $12 \mathrm{~cm}$ Petri dish. Plates were incubated at $25^{\circ} \mathrm{C}$ for 3-5 days, checked for fungal outgrowth from each kernel. Hyphae from Fusarium colonies on PDA were transferred to a fresh poor-nutrient potato dextrose agar (half strength PDA) (potato infusion $100 \mathrm{~g}$, dextrose $20 \mathrm{~g}$, agar $20 \mathrm{~g}$, distilled water $1000 \mathrm{ml}$ ) plate and the culture was grown for 5 to 7 days. Single spores were separated with an inoculation needle under stereomicroscope and transferred to individual PDA plates. All Fusarium isolates were stored in $30 \%$ glycerin, at $-80{ }^{\circ} \mathrm{C}$ at the IPP-LAAS, Shenyang, China.

\section{Morphological examination of Fusarium spp.}

The isolates were identified based on morphological characteristics (Leslie and Summerell, 2006). Strains of Fusarium spp. were grown at $25^{\circ} \mathrm{C}$ on carnation leaf agar, synthetic nutrient-poor agar (SNA) as well as PDA. Growth rates and colony diameters of cultures incubated for 5 days in the dark were measured on both SNA and PDA. Characteristics, such as size and shape of conidia, the presence of phialides and chlamydospores were recorded from strains grown on CLA or SNA incubated in the dark for 10-14 days. Presence of polyphialides on SNA, CLA and development of sporodochia on PDA was also examined in 4-week old cultures. Polyphialides were identified after staining the fungal structures with cotton blue in lactic 
acid. Macroscopic characters, such as surface texture and colony colours, were described from PDA.

\section{Molecular identification of Fusarium spp.}

\section{DNA manipulation}

Fusarium isolates were grown in shaken cultures $(140$ rpm) at $26^{\circ} \mathrm{C}$ for 4 days in $100 \mathrm{ml}$ flasks containing $50 \mathrm{ml}$ potato-dextrose broth medium. Mycelium was harvested by filtration though cheesecloth and freeze-dried. 10 to 20 $\mathrm{mg}$ freeze-dried mycelium was grinded in a 1.5 micro tube with help of glass beads for $10 \mathrm{~s}$ at 4,000 rpm, $450 \mu \mathrm{l}$ cell lysis solution (Gentra Puregene Buccal Cell Kit, Qiagen, Germantown, MD, USA) plus $3 \mu \mathrm{l}$ proteinase $(20 \mathrm{mg} / \mu \mathrm{l})$ was added and the tube was incubated for $1 \mathrm{~h}$ at $55^{\circ} \mathrm{C}$. To remove proteins, $150 \mu \mathrm{l}$ of protein precipitation solution was added to the cell-lysate and vortexed for $20 \mathrm{~s}$ at high speed to mix well. After protein precipitation the samples were centrifugated and the supernatant transferred to a new tube containing $300 \mu \mathrm{l} 100 \%$ isopropanol. The tubes were stored at $-20{ }^{\circ} \mathrm{C}$ for $10 \mathrm{~min}$ and DNA was pelleted at 1,400 rpm for $10 \mathrm{~min}$. The pellet was washed with 300 $\mu \mathrm{l} 70 \%$ ethanol and centrifuged again for $10 \mathrm{~min}$. After removal of the supernatant the pellet was airdried at $65^{\circ} \mathrm{C}$ for $10 \mathrm{~min}$ and $50 \mu \mathrm{l}$ distilled water was added to the pellet. RNA was degraded by incubation with RNases $(10 \mathrm{mg} / \mu \mathrm{l})$ for $30 \mathrm{~min}$ at $37^{\circ} \mathrm{C}$. Gel electrophoresis was used to estimate the concentration and integrity of the DNA.

\section{Molecular identification of Fusarium species}

Molecular identification of Fusarium isolates was done using established PCR protocols described in literature (Mishra et al., 2003; Mulè et al., 2004; Nicholson et al., 1998; O'Donnell et al., 1998) and primers used are listed in Table 2. After amplification PCR products were analysed on agarose gels to confirm species identity.

\section{Sequencing the elongation factor gene}

The translation elongation factor gene EF- $1 \alpha$ was amplified with the primers EF-1 and EF-2 (Table 2) as previously described (O'Donnell et al., 2004). PCR was performed and each PCR reaction $(50 \mu \mathrm{l})$ contained $5.0 \mu \mathrm{l}$ DNA template. Reactions were performed using a GeneAmp PCR System 9700 thermal cycler (Thermo Fisher, Waltham, MA, USA) programmed for $94{ }^{\circ} \mathrm{C}$ for $5 \mathrm{~min}$; followed by 35 cycles of $\left(95{ }^{\circ} \mathrm{C}\right.$ for $50 \mathrm{~s}, 53{ }^{\circ} \mathrm{C}$ for $50 \mathrm{~s}$, and $72{ }^{\circ} \mathrm{C}$ for $60 \mathrm{~s}$ ) and then a final extension at $72^{\circ} \mathrm{C}$ for $10 \mathrm{~min}$. The amplified PCR products were bi-directionally sequenced by Dingguo Biotech (Beijing, China P.R.) and the sequences were compared with DNA sequences in the Fusarium ID database at Penn State University (USA).

\section{Molecular identification of toxigenic genes}

The detection of the FUM1 gene was conducted using the specific primers: PQF5-F/PQF5-R for $F$. verticillioides isolates, FUM5P2-F/FUM5P2-F for $F$. proliferatum strains, and FUM1-F/FUM1-R for all other Fusarium species, respectively (Table 3 ). The molecular determination of the chemotypes of isolates from the Fusarium graminearum species complex (FGSC), including $F$. graminearum, Fusarium asiaticum and Fusarium meridionale was conducted using specific primers: Tri13F/DON, Tri13NIV/R and ToxP1/ToxP2 for identification of DON and NIV producers, respectively. To discriminate among DON producers, primer pair Tri303F/R was used for the identification of 3-acetyldeoxynivalenol (3-ADON) producers and primer pair Tri315F/R for 15-acetyldeoxynivalenol (15-ADON) producers. Electrophoretic analysis of the PCR amplified products was performed on a $1 \%$ agarose gel.

Table 2. Primers used for identification of Fusarium species in this study.

\begin{tabular}{|c|c|c|c|c|c|}
\hline Primer & Primer sequence & Fusarium species & Temperature $\left({ }^{\circ} \mathrm{C}\right)$ & Product size (bp) & References \\
\hline VER1 & СTTCCTGCGATGTTTCTCC & F. verticillioides & 56 & 578 & Mulè et al., 2004 \\
\hline VER2 & AATTGGCCATTGGTATTATATATCTA & & & & \\
\hline PRO1 & CTTTCCGCCAAGTTTCTTC & F. proliferatum & 56 & 585 & Mulè et al., 2004 \\
\hline PRO2 & TGTCAGTAACTCGACGTTGTTG & & & & \\
\hline SUB1 & CTGTCGCTAACCTCTTTATCCA & F. subglutinans & 56 & 631 & Mulè et al., 2004 \\
\hline SUB2 & CAGTATGGACGTTGGTATTATATCTAA & & & & \\
\hline FoF1 & ACATACCACTTGTTGCCTCG & F. oxysporum & 58 & 340 & Mishra et al., 2003 \\
\hline FoR1 & CGCCAATCAATTTGAGGAACG & & & & \\
\hline $\mathrm{Fg} 16 \mathrm{NF}$ & ACAGATGACAAGATTCAGGCACA & F. graminearum & 57 & 280 & Nicholson et al., 1998 \\
\hline Fg16NR & TTCTTTGACATCTGTTCAACCСA & & & & \\
\hline EF-1 & ATGGGTAAGGAGGACAAGAC & Fusarium spp. & 58 & 750 & O'Donnell et al., 2004 \\
\hline $\mathrm{EF}-2$ & GGAAGTACCAGTGATCATGTT & & & & \\
\hline
\end{tabular}


Table 3. Primer used for identification of toxigenic genes in this study.

\begin{tabular}{|c|c|c|c|c|c|}
\hline Primer & Primer sequence & $\begin{array}{l}\text { PCR } \\
\text { conditions }\end{array}$ & Amplicon (bp) & $\begin{array}{l}\text { Mycotoxin } \\
\text { chemotype }^{1}\end{array}$ & Reference \\
\hline Tri13F & CATCATGAGACTTGTKCRAGTTTGGG & $58^{\circ} \mathrm{C}, 45 \mathrm{~s}$ & 282 & DON & Chandler et al., 2003 \\
\hline Tri13RDON & GCTAGATCGATTGTTGCATTGAG & & & & \\
\hline Tri13R & TTGAAAGCTCCAATGTCGTG & $58^{\circ} \mathrm{C}, 45 \mathrm{~s}$ & 312 & NIV & Chandler et al., 2003 \\
\hline Tri13NIV & CCAAATCCGAAAACCGCAG & & & & \\
\hline Tri303F & GATGGCCGCAAGTGGA & $55^{\circ} \mathrm{C}, 30 \mathrm{~s}$ & 586 & 3-ADON & Jennings et al., 2004 \\
\hline Tri303R & GCCGGACTGCCCTATTG & & & & \\
\hline Tri315F & CTCGCTGAAGTTGGACGTAA & $58^{\circ} \mathrm{C}, 45 \mathrm{~s}$ & 864 & 15-ADON & Jennings et al., 2004 \\
\hline Tri315R & GTCTATGCTCTCAACGGACAAC & & & & \\
\hline ToxP1 & GCCGGGGGRTAAAAGTCAAA & $55^{\circ} \mathrm{C}, 60 \mathrm{~s}$ & 300 & DON & Li et al., 2005 \\
\hline ToxP2 & TGACAAGTCCGGTCGCACTAGCA & & 360 & NIV & \\
\hline PQF5-F & GAGCCGAGTCAGCAAGGATT & $60^{\circ} \mathrm{C}, 60 \mathrm{~s}$ & 70 & FUM (F. vert) & López-Errasquín et al., 2007 \\
\hline PQF5-R & AGGGTTCGTGAGCCAAGGA & & & & \\
\hline FUM5P2-F & СССССАTCATCCCGAGTAT & $60^{\circ} \mathrm{C}, 60 \mathrm{~s}$ & 60 & FUM (F. prol) & López-Errasquín et al., 2007 \\
\hline FUM5P2-R & TGGGTCCGATAGTGATTTGTCA & & & & \\
\hline FUM1-F & CCATCACAGTGGGACACAGT & $56^{\circ} \mathrm{C}, 50 \mathrm{~s}$ & 183 & FUM1 & Bluhm et al., 2004 \\
\hline FUM1-R & CGTATCGTCAGCATGATGTAGC & & & & \\
\hline
\end{tabular}

${ }^{1}$ DON = deoxynivalenol; NIV = nivalenol; 3-/15-ADON = 3-/15-deoxynivalenol; FUM = fumonisin.

\section{Results}

\section{Population structure of Fusarium species associated with maize ear rot}

Based on morphology and molecular assay results, a total of 1,022 Fusarium isolates encompassing eight Fusarium species were identified, including $F$. verticillioides, $F$. graminearum, F. proliferatum, Fusarium subglutinans, $F$. meridionale, Fusarium oxysporum, Fusarium semitectum, and $F$. asiaticum, with isolation frequencies of $75.34 \%$ ( $\mathrm{n}=770), 8.32 \%$ (85), 7.14\% (73), 4.11\% (42), 1.57\% (16), $1.37 \%(14), 1.17 \%(12)$, and $0.98 \%$ (10), respectively (Figure 1). F. verticillioides was dominant in all regions ranging from 63.63 to $87.85 \%$ of the isolates retrieved. There were differences in the number of isolates and the frequency of Fusarium species across different provinces of China. The number of Fusarium species from maize kernels in Liaoning, Jilin, Hebei and Hubei provinces were higher than that in other provinces. The distribution of Fusarium species is also different among provinces with eight Fusarium species in Hubei province. F. asiaticum was found in Liaoning, Jilin, Shandong and Hubei province. $F$. meridionale was only found in the south of China, such as Hubei, Sichuan and Guizhou province.

\section{Detection of toxigenic genes and chemotypes}

\section{Detection of trichothecene chemotypes of FGSC members associated with maize ear rot in different provinces of China}

The total of 111 isolates of the FGSC, including $85 F$. graminearum, $10 \mathrm{~F}$. asiaticum and $16 \mathrm{~F}$. meridionale from 12 provinces of China, was tested for trichothecene chemotypes using specific primers (Table 4). All of 85 F. graminearum isolates were of the DON chemotype based on the Tri13F/DON, Tri13NIV/R and ToxP1/P2 assays and more specifically all were of the 15-ADON type as determined by the primer pairs Tri303F/R and Tri315F/R. The ten $F$. asiaticum and $16 F$. meridionale isolates were all of the NIV chemotype as determined by the Tri13F/DON, Tri13NIV/R and ToxP1/P2 assays (Table 4).

Detection of the FUM gene in members of Fusarium fujikuroi species complex associated with maize ear rot in provinces of China

Using the specific primer pairs of PQF5-F/R, FUM5P2-F/R and FUM1F/R, the presence of the fumonisin polyketide synthase gene was detected in 432 out of $770 \mathrm{~F}$. verticillioides (56.10\%) and 32 out of $73 \mathrm{~F}$. proliferatum (43.84\%) while none of the 42 F. subglutinans isolates tested positive with one or more of these primer combinations (Table 5). The proportion of fumonisin producing $F$. verticillioides strains was different across the 12 provinces ranging from $32.39 \%$ (Hebei province) to $70.21 \%$ (Shanxi province). Among the 


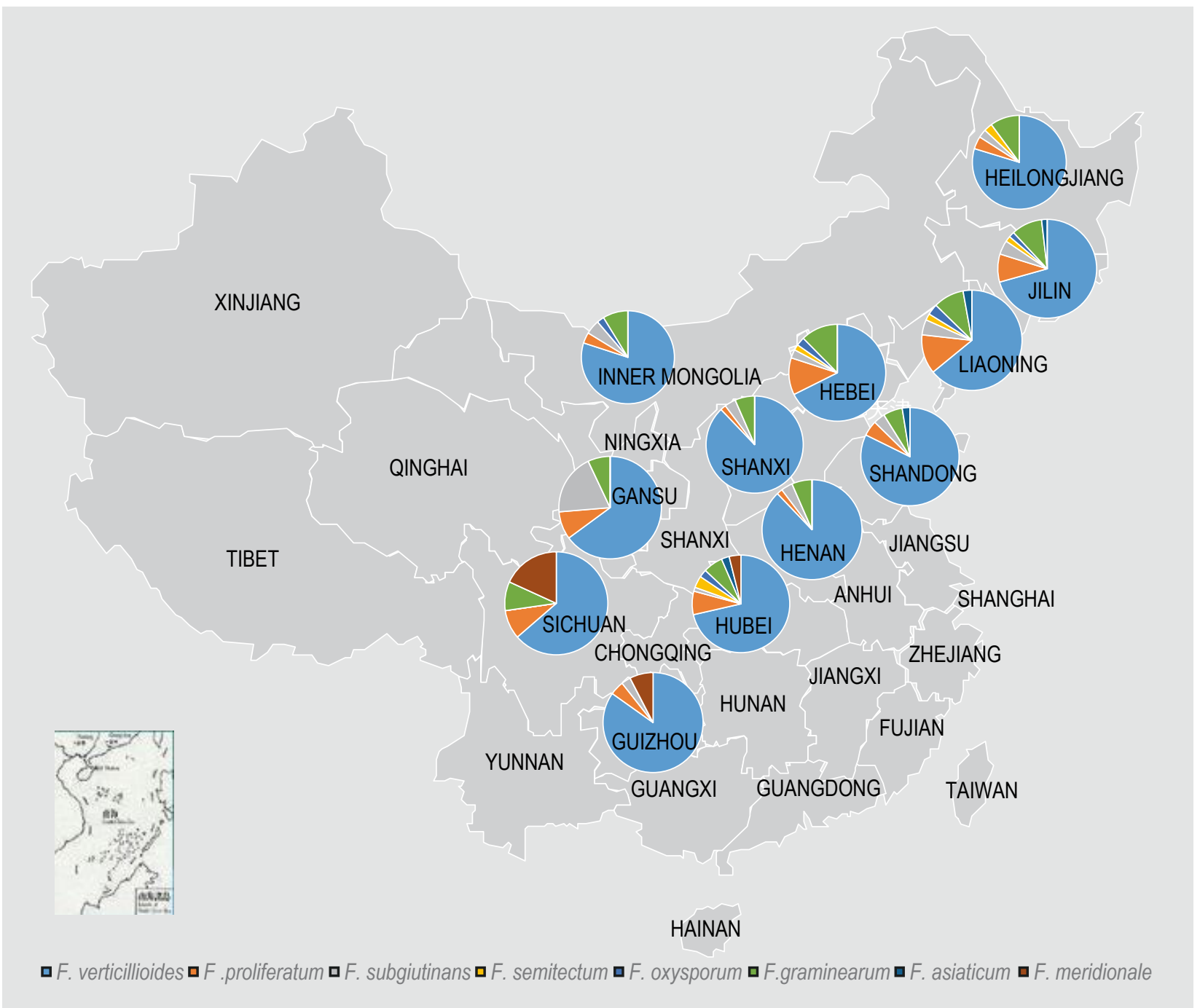

Figure 1. Distribution of Fusarium species associated with maize ear rot in different provinces.

73 F. proliferatum isolates fumonisin producers ranged from 20.00\% in Gansu province to 100\% in Inner Mongolia, Shanxi and Guizhou.

\section{Discussion}

Maize is an important food crop in the world and has become more popular as well in China. Fusarium ear rot, FER, is an important disease in most countries were maize is grown. FER not only results in yield losses and the reduction of seed quality, the pathogens involved accumulate mycotoxins in infected tissues that could have dangerous consequences on human and animal health (Bottalico, 1998). Fumonisins, trichothecenes (DON, NIV and derivatives) and ZEN are the most prominent mycotoxins produced by Fusarium species that contaminate maize. Members of the Fusarium fujikuroi species complex, including $F$. verticillioides, $F$. proliferatum and $F$. subglutinans, are the most important and prevalent species, causing ear rot world-wide (Bottalico, 1998). In China, studies on mycotoxins in maize focused mainly on detection methods, such as high-performance liquid chromatography (HPLC), rather than on the causal agents, the toxigenic Fusarium species. Wang et al. (2006) collected 284 maize samples from six provinces of China and detected DON in $67 \%$ of the samples ranging from 10 to $3,800 \mu \mathrm{g} / \mathrm{kg}$ using gas chromatography. More recently, Wang et al. (2016) collected maize samples in Shandong province for mycotoxin contamination demonstrating that the incidences and average contents of FBs (fumonisin $B_{1}, B_{2}$ and $B_{3}$ ), DON, and ZEN increased from harvest to storage period. Due to the co-occurrence of mycotoxins and their cumulative toxic effects, there is an urgent need for quality control to warrant safe produce.

\section{Species identification}

Previous studies on maize ear rot in China focus on symptomatic plant parts (Guo et al., 2014) in which $F$. verticillioides and $F$. graminearum were identified as the predominant species (Qin et al., 2014; Qu et al., 2009). 
Table 4. Detection of mycotoxin chemotypes of Fusarium graminearum species complex members associated with maize ear rot in provinces of China.

\begin{tabular}{|c|c|c|c|c|c|c|c|c|}
\hline \multirow[t]{3}{*}{ Isolate codes } & \multirow{3}{*}{$\begin{array}{l}\text { Fusarium } \\
\text { species }^{1}\end{array}$} & \multirow[t]{3}{*}{ Origin } & \multicolumn{2}{|l|}{ ToxP gene ${ }^{2}$} & \multicolumn{2}{|l|}{ Tri13 gene ${ }^{2}$} & \multicolumn{2}{|l|}{ Tri3 gene ${ }^{2}$} \\
\hline & & & ToxP1/DON & ToxP2/NIV & Tri13F/DON & Tri13NIV/R & Tri303F/R/3- & Tri315F/ \\
\hline & & & & & & & ADON & R/15-ADON \\
\hline HLJFG01 & FG & Heilonlongjiang & + & - & + & - & - & + \\
\hline HLJFG02 & FG & Heilonlongjiang & + & - & + & - & - & + \\
\hline HLJFG03 & FG & Heilonlongjiang & + & - & + & - & - & + \\
\hline HLJFG04 & FG & Heilonlongjiang & + & - & + & - & - & + \\
\hline HLJFG05 & FG & Heilonlongjiang & + & - & + & - & - & + \\
\hline HLJFG06 & FG & Heilonlongjiang & + & - & + & - & - & + \\
\hline HLJFG07 & FG & Heilonlongjiang & + & - & + & - & - & + \\
\hline JLFG01 & FG & Jilin & + & - & + & - & - & + \\
\hline JLFG02 & FG & Jilin & + & - & + & - & - & + \\
\hline JLFG03 & FG & Jilin & + & - & + & & - & + \\
\hline JLFG04 & FG & Jilin & + & - & + & - & - & + \\
\hline JLFG05 & FG & Jilin & + & - & + & & - & + \\
\hline JLFG06 & FG & Jilin & + & - & + & - & - & + \\
\hline JLFG07 & FG & Jilin & + & - & + & - & - & + \\
\hline JLFG08 & FA & Jilin & - & + & - & + & - & - \\
\hline JLFG09 & FA & Jilin & - & + & - & + & - & - \\
\hline JLFG010 & FG & Jilin & + & - & + & - & - & + \\
\hline JLFG011 & FG & Jilin & + & - & + & - & - & + \\
\hline LN01 & FG & Liaoning & + & - & + & - & - & + \\
\hline LNO2 & FG & Liaoning & + & - & + & - & - & + \\
\hline LN03 & FG & Liaoning & + & - & + & - & - & + \\
\hline LN04 & FG & Liaoning & + & - & + & - & - & + \\
\hline LN05 & FG & Liaoning & + & - & + & - & - & + \\
\hline LN06 & FG & Liaoning & + & - & + & - & - & + \\
\hline LN07 & FG & Liaoning & + & - & + & - & - & + \\
\hline LN08 & FA & Liaoning & - & + & - & + & - & - \\
\hline LN09 & FA & Liaoning & - & + & - & + & - & - \\
\hline LN10 & FG & Liaoning & + & - & + & - & - & + \\
\hline LN11 & FA & Liaoning & - & + & - & + & - & - \\
\hline LN12 & FA & Liaoning & - & + & - & + & - & - \\
\hline LN13 & FG & Liaoning & + & - & + & - & - & + \\
\hline LN14 & FG & Liaoning & + & - & + & - & - & + \\
\hline LN15 & FG & Liaoning & + & - & + & - & - & + \\
\hline LN16 & FG & Liaoning & + & - & + & - & - & + \\
\hline LN17 & FG & Liaoning & + & - & + & - & - & + \\
\hline LN18 & FG & Liaoning & + & - & + & - & - & + \\
\hline LN19 & FA & Liaoning & - & + & - & + & - & - \\
\hline IM01 & FG & Inner Mongolia & + & - & + & - & - & + \\
\hline IM02 & FG & Inner Mongolia & + & - & + & - & - & + \\
\hline IM03 & FG & Inner Mongolia & + & - & + & - & - & + \\
\hline IM04 & FG & Inner Mongolia & + & - & + & - & - & + \\
\hline IM05 & FG & Inner Mongolia & + & - & + & - & - & + \\
\hline IM06 & FG & Inner Mongolia & + & - & + & - & - & + \\
\hline IM07 & FG & Inner Mongolia & + & - & + & - & - & + \\
\hline HEB01 & FG & Hebei & + & - & + & - & - & + \\
\hline HEB02 & FG & Hebei & + & - & + & - & - & + \\
\hline HEB03 & FG & Hebei & + & - & + & - & - & + \\
\hline HEBO4 & FG & Hebei & + & - & + & - & - & + \\
\hline
\end{tabular}


Table 4. Continued.

\begin{tabular}{|c|c|c|c|c|c|c|c|c|}
\hline \multirow[t]{2}{*}{ Isolate codes } & \multirow{2}{*}{$\begin{array}{l}\text { Fusarium } \\
\text { species }^{1}\end{array}$} & \multirow[t]{2}{*}{ Origin } & \multicolumn{2}{|l|}{ ToxP gene ${ }^{2}$} & \multicolumn{2}{|l|}{ Tri13 gene ${ }^{2}$} & \multicolumn{2}{|l|}{ Tri3 gene ${ }^{2}$} \\
\hline & & & ToxP1/DON & ToxP2/NIV & Tri13F/DON & Tri13NIV/R & $\begin{array}{l}\text { Tri303F/R/3- } \\
\text { ADON }\end{array}$ & $\begin{array}{l}\text { Tri315F/ } \\
\text { R/15-ADON }\end{array}$ \\
\hline HEB05 & FG & Hebei & + & - & + & - & - & + \\
\hline HEB06 & FG & Hebei & + & - & + & - & - & + \\
\hline HEB07 & FG & Hebei & + & - & + & - & - & + \\
\hline HEB08 & FG & Hebei & + & - & + & - & - & + \\
\hline HEB09 & FG & Hebei & + & - & + & - & - & + \\
\hline HEB10 & FG & Hebei & + & - & + & - & - & + \\
\hline HEB11 & FG & Hebei & + & - & + & - & - & + \\
\hline HEB12 & FG & Hebei & + & - & + & - & - & + \\
\hline HEB13 & FG & Sandong & + & - & + & - & - & + \\
\hline SD01 & FG & Sandong & + & - & + & - & - & + \\
\hline SD02 & FG & Sandong & + & - & + & - & - & + \\
\hline SD03 & FG & Sandong & + & - & + & - & - & + \\
\hline SD04 & FG & Sandong & + & - & + & - & - & + \\
\hline SD05 & FA & Sandong & - & + & - & + & - & - \\
\hline SD06 & FA & Sandong & - & + & - & + & - & - \\
\hline SD06 & FA & Sandong & - & + & - & + & - & - \\
\hline SX01 & FG & Shanxi & + & - & + & - & - & + \\
\hline SX02 & FG & Shanxi & + & - & + & - & - & + \\
\hline SX03 & FG & Shanxi & + & - & + & - & - & + \\
\hline SX04 & FG & Shanxi & + & - & + & - & - & + \\
\hline SX05 & FG & Shanxi & + & - & + & - & - & + \\
\hline sX06 & FG & Shanxi & + & - & + & - & - & + \\
\hline SX07 & FG & Shanxi & + & - & + & - & - & + \\
\hline HN01 & FG & Henan & + & - & + & - & - & + \\
\hline HN02 & FG & Henan & + & - & + & - & - & + \\
\hline HNO3 & FG & Henan & + & - & + & - & - & + \\
\hline HNO4 & $\mathrm{FM}$ & Henan & - & + & - & + & - & - \\
\hline HNO5 & $\mathrm{FM}$ & Henan & - & + & - & + & - & - \\
\hline HN06 & FG & Henan & + & - & + & - & - & + \\
\hline $\mathrm{HNO7}$ & FG & Henan & + & - & + & - & - & + \\
\hline HN08 & FG & Henan & + & - & + & - & - & + \\
\hline HNO9 & FG & Henan & + & - & + & - & - & + \\
\hline HN10 & FG & Henan & + & - & + & - & - & + \\
\hline HN11 & FG & Henan & + & - & + & - & - & + \\
\hline HUB01 & FG & Hubei & + & - & + & - & - & + \\
\hline HUB02 & FM & Hubei & - & + & - & + & - & - \\
\hline HUB03 & FM & Hubei & - & + & - & + & - & - \\
\hline HUBO4 & FG & Hubei & + & - & + & - & - & + \\
\hline HUB05 & FG & Hubei & + & - & + & - & - & + \\
\hline HUB06 & FG & Hubei & + & - & + & - & - & + \\
\hline HUB07 & FG & Hubei & + & - & + & - & - & + \\
\hline HUB08 & FG & Hubei & + & - & + & - & - & + \\
\hline HUB09 & FG & Hubei & + & - & + & - & - & + \\
\hline HUB09 & FG & Hubei & + & - & + & - & - & + \\
\hline HUB10 & $\mathrm{FM}$ & Hubei & - & + & - & + & - & - \\
\hline GS01 & FG & Gansu & + & - & + & - & - & + \\
\hline GS02 & FG & Gansu & + & - & + & - & - & + \\
\hline GS03 & FG & Gansu & + & - & + & - & - & + \\
\hline GS04 & FG & Gansu & + & - & + & - & - & + \\
\hline
\end{tabular}


Table 4. Continued.

\begin{tabular}{|c|c|c|c|c|c|c|c|c|}
\hline \multirow[t]{2}{*}{ Isolate codes } & \multirow{2}{*}{$\begin{array}{l}\text { Fusarium } \\
\text { species }^{1}\end{array}$} & \multirow[t]{2}{*}{ Origin } & \multicolumn{2}{|l|}{ ToxP gene ${ }^{2}$} & \multicolumn{2}{|l|}{ Tri13 gene $^{2}$} & \multicolumn{2}{|l|}{ Tri3 gene ${ }^{2}$} \\
\hline & & & ToxP1/DON & ToxP2/NIV & Tri13F/DON & Tri13NIV/R & $\begin{array}{l}\text { Tri303F/R/3- } \\
\text { ADON }\end{array}$ & $\begin{array}{l}\text { Tri315FI } \\
\text { R/15-ADON }\end{array}$ \\
\hline GZ01 & $\mathrm{FM}$ & Guizhou & - & + & - & + & - & - \\
\hline GZ02 & $\mathrm{FM}$ & Guizhou & - & + & - & + & - & - \\
\hline GZO3 & $\mathrm{FM}$ & Guizhou & - & + & - & + & - & - \\
\hline GZO4 & $\mathrm{FM}$ & Guizhou & - & + & - & + & - & - \\
\hline GZ05 & $\mathrm{FM}$ & Guizhou & - & + & - & + & - & - \\
\hline SC01 & FG & Sichuan & + & - & + & - & - & + \\
\hline SC02 & FG & Sichuan & + & - & + & - & - & + \\
\hline SC03 & FG & Sichuan & + & - & + & - & - & + \\
\hline SC04 & $\mathrm{FM}$ & Sichuan & - & + & - & + & - & - \\
\hline SC05 & $\mathrm{FM}$ & Sichuan & - & + & - & + & - & - \\
\hline SC06 & FM & Sichuan & - & + & - & + & - & - \\
\hline SC07 & $\mathrm{FM}$ & Sichuan & - & + & - & + & - & - \\
\hline SC08 & $\mathrm{FM}$ & Sichuan & - & + & - & + & - & - \\
\hline SC09 & $\mathrm{FM}$ & Sichuan & - & + & - & + & - & - \\
\hline
\end{tabular}

Table 5. Detection of the capacity of fumonisin (FUM) production of in members of Fusarium fujikuroi species complex associated with maize ear rot in 12 provinces in China. ${ }^{1}$

\begin{tabular}{|c|c|c|c|c|c|c|c|c|c|c|c|c|c|c|}
\hline $\begin{array}{l}\text { Fusarium } \\
\text { species }\end{array}$ & Isolates & $\begin{array}{l}\text { Total } \\
\text { number }\end{array}$ & HLJ & JL & LN & IM & HEB & SD & sX & HN & HUB & GS & GZ & SC \\
\hline \multirow[t]{3}{*}{ F. verticillioides } & Number & 770 & 55 & 77 & 91 & 64 & 71 & 65 & 94 & 84 & 55 & 37 & 56 & 21 \\
\hline & FUM & 432 & 33 & 45 & 56 & 29 & 23 & 45 & 66 & 45 & 28 & 21 & 31 & 10 \\
\hline & Frequency (\%) & 56.10 & 60.00 & 58.44 & 61.54 & 45.31 & 32.39 & 69.23 & 70.21 & 53.57 & 50.91 & 56.76 & 55.36 & 47.62 \\
\hline \multirow[t]{3}{*}{ F. proliferatum } & Number & 73 & 3 & 10 & 18 & 3 & 13 & 4 & 2 & 3 & 6 & 5 & 3 & 3 \\
\hline & FUM & 32 & 1 & 4 & 5 & 3 & 5 & 3 & 2 & 2 & 4 & 1 & 3 & 1 \\
\hline & Frequency (\%) & 43.84 & 33.33 & 40.00 & 27.78 & 100 & 38.46 & 75.0 & 100 & 66.67 & 66.67 & 20.00 & 100 & 33.33 \\
\hline
\end{tabular}

\footnotetext{
${ }^{1}$ HLJ = Heilongjiang; JL = Jilin; LN = Liaoning; IM = Inner Mongolia; HEB = Hubei; SD = Shandong; SX = Shanxi; HN =Henan; HUB = Hubei; GS =
} Gansu; GZ = Guizhou; SC = Sichuan.

However, sampling of symptomatic plant tissue creates a bias and as symptomatic kernels and cobs may be discarded by maize producers; this may not represent the actual risks. In addition, many samplings in China have been performed on a provincial or regional level. To allow a more comprehensive and less biased sampling, we performed a structured sampling using a fixed set of cultivars, unified harvest time as well as unified grain drying in the laboratory to reduce contamination and/or outgrowth of Fusarium spp. after harvest. This evaluation of the Fusarium species associated with maize ear rot provides a new instrument to monitor maize throughout China. To collect data on the Fusarium species and mycotoxins that are present in maize the establishment of a China database is required. In addition, storing the isolates in viable cultures will provide a reference for future studies. In this study, Fusarium species from maize kernel samples in 12 provinces of China were identified by morphological and molecular techniques. The results indicated that Fusarium species associated with maize ear rot include $F$. verticillioides, F. graminearum, $F$. proliferatum, F. subglutinans, F. meridionale, F. oxysporum, F. semitectum and F. asiaticum, respectively. F. verticillioides and F. graminearum were found to be the dominant species on asymptomatic kernels. Since the incidence of Fusarium 
spp. in asymptomatic kernels is lower than in symptomatic kernels, this indicates that the pathogen is already present, but somehow triggered to proliferate on the maize cobs.

\section{Toxin capacity}

Both $F$. verticillioides and F. proliferatum theoretically possess the capacity to synthesise FBs. Several PCR based assays were previously described to detect the genes responsible for FBs production (Bluhm et al., 2004; LópezErrasquín et al., 2007). We used these assays to screen our F. verticillioides, F. proliferatum and F. subglutinans isolates. As expected in none of $F$. subglutinans isolates the primers were able to amplify the FUM amplicon. However, to our surprise also in a large proportion of the $F$. verticillioides and $F$. proliferatum isolates the expected amplicon using the primer pairs PQF5-F/R or FUM5P2-F/R was not obtained. This cannot be caused by quality or quantity of the DNA preparations, since amplicons were generated with the EF primers as well as with the species-specific primers. This lack of amplification might be due to diversity at the primer sites. If this would be true, it would have important implications for the use of these primers to detect fumonisin producing species leading to an underestimation of the problem. Also other researchers have reported this problem. Cheri (2016) applied the PCR assay based on the FUM gene to identify the genetic potential of FUM production of the FFSC strains isolated from ears of wild grasses in Iran and observed that out of 22 isolates only 11 (50\%) were determined as fumonisin producers.

Among the trichothecene genotypes, DON was the predominant mycotoxin in maize production areas of China, with all $85 \mathrm{~F}$. graminearum isolates showing the 15-ADON chemotype. Remarkably, none of the $F$. asiaticum isolates showed the 3-ADON chemotype that was previously found to be the dominant species on wheat, rice and barley (Zhang et al., 2010, 2012). In addition, a clear association between the different chemotypes and the species was found: all $F$. asiaticum $(\mathrm{n}=10)$ and $F$. meridionale $(\mathrm{n}=16)$ isolates had the NIV chemotype even when they were isolated from the same maize field.

\section{Population diversity}

Our study does not reveal much of the population diversity within the species. The large set of $F$. verticillioides and the different locations from which the isolates originate could be used for such studies. However, a consensus on established methods for diversity studies is currently lacking. Microsatellite distribution in the F. verticillioides genome is similar to other ascomycetes, but unlike other previously analysed fungal genomes, the $F$. verticillioides genome has a high frequency of hexanucleotides (LeyvaMadrigal et al., 2014; Reynoso et al., 2009). Consensus on markers, protocols and scoring is required to set up a global genotyping protocol as was previously established for $F$. graminearum (Suga et al., 2008). Harmonising such efforts can be complicated and perhaps in the future such diversity studies can be performed by whole genome sequencing, or mitochondrial sequencing applying next generation sequencing. The collection described in this study and the identification and characterisation of the isolates could be the start of a global database for Fusarium isolates including FER isolates as was previously established for Fusarium isolates collected from wheat, rice and barley (https:// emdelponte.github.io/FGSC/ or https://twitter.com/ edelponte/status/898013549758472196). Such a repository would allow more comprehensive studies and monitoring of changes in Fusarium populations.

\section{Solutions}

The growth of fumonisin-producing Fusarium species and the synthesis of mycotoxins in maize are greatly influenced by multiple environmental factors in different geographical areas, including climate, temperature, humidity and rainfall prior to and during pre-harvest and harvest periods, as well as other factors, such as insect infestation and agricultural practices. Processing and storage are key factors to control and reduce toxin contamination (Magan et al., 2003). Our study shows that in China asymptomatic infections with toxigenic Fusarium species are very common. It is therefore important to raise awareness and to improve post-harvest practices. Currently, the storage conditions in China for harvested maize are not optimal and may aggravate the contamination of maize grain by fungi and/or increase mycotoxin production by toxigenic fungi. Particularly, the storage facilities and storage conditions should be improved. In addition, development and application of resistant hybrids may prevent both ear rot progress as well as mycotoxin contamination. Although genetic variation for resistance to Fusarium ear rot is present among inbred lines and hybrids in field maize, there is no complete resistance to either ear rot or fumonisin accumulation (Presello et al., 2008; Xu et al., 2019). In recent years, more and more attention has been given to the breeding of maize ear rot resistant varieties in China (Li et al., 2018; Zou et al., 2017). As the assessment of resistance is often done visually, immediately after harvest, it is not clear whether asymptomatic kernels of cultivars evaluated as resistant do not pose a mycotoxin risk after storage. A comprehensive monitoring is required to critically evaluate these risks.

\section{Acknowledgements}

The research was sponsored by National Key R\&D Program of China (2016YFE0112900) and by the European Union's Horizon 2020 research and innovation programme under grant agreement No 678781 (MycoKey). 


\section{Conflict of interest}

The authors declare no conflict of interest.

\section{References}

Bai, J.K., 1997. Cereal crops disease. China agricultural press, Beijing, China P.R.

Bluhm, B.M., Cousin, M.A., and Woloshuk, C.P., 2004. Multiplex realtime PCR detection of fumonisins producing and trichothecene producing groups of Fusarium species. Journal of Food Protection 3: 536-543.

Bottalico, A., 1998. Fusarium disease of cereals: Species complex and related mycotoxin profiles. European Journal of Plant Pathology 80: 85-103.

Council for Agricultural Science and Technology (CAST), 2003. Mycotoxins: risks in plant, animal and human systems. Task force report No. 139. Ames, IA, USA.

Chandler, E.A., Simpson, D.R., Thomsett, M.A. and Nicholson, P., 2003. Development of PCR assays to Tri7 and Tr13 trichothecene biosynthetic genes, and characterization of chemotypes of Fusarium graminearum, F. culmorum and F. cerealis. Physiological and Molecular Plant Pathology 62: 355-367

Cheri, K.H., 2016. Detection of the fumonisin-producing Fusarium fujikuroi species complex (FFSC), associated with wild grasses in Iran. Mycologia Iranica 3: 121-126.

Gao, X.M., Lu, G.Z., Sun, X.D., Liu, S.Q. and Chen, R., 2005. Diversity of maize seed borne Fungi. Journal of Fungal Research 3: 42-46.

Guo, C., Wei, H.Y., Guo, M.K., He, S.Q., Jin, S.L., Chen, H.M., Wang, X.M. and Guo, J.G., 2014. Isolation, identification and biological characteristics of Fusarium verticillioides from maize ear rot samples in Gansu Province. Acta Phytopathologica Sinica 44: 17-25.

Jennings, P., Coates, M.E., Turner, J.A., Chandler, E.A. and Nicholson, P., 2004. Determination of deoxynivalenol and nivalenol chemotypes of Fusarium culmorum isolates from England and Wales by PCR assay. Plant Pathology 53: 182-190.

Leyva-Madrigal K.Y., Larralde-Corona C.P., Calderón-Vázquez, C.L. and Maldonado-Mendoza, E., 2014. Genome distribution and validation of novel microsatellite markers of Fusarium verticillioides and their transferability to other Fusarium species. Journal of Microbiological Methods 101: 18-23.

Leslie, J.F. and Summerell, B.A., 2006. The Fusarium laboratory manual. Blackwell Publishing, Ames, IA, USA.

Li, H.P., Wu, A.B., Zhao, C.S., Scholten, O., Löffler, H. and Liao, Y.C., 2005. Development of a generic PCR detection of deoxynivalenol and nivalenol chemotypes of Fusarium graminearum. FEMS Microbiology Letters 243: 505-511.

Li, X.Y., Ma, Z.J., Gai, X.T., Wang, H.D., Yao, Y., Sun, Y.Q. and Gao, Z.G., 2018. Identification of Fusarium species associated with maize ear rot in northeast China and the diversity of Fusarium verticillioides. Journal of Shenyang Agricultural University 49:136-142.

López-Errasquín, E., Vázquez, C., Jiménez, M. and González-Jaén, M.T., 2007. Real-time RT-PCR assay to quantify the expression of fum1 and fum19 genes from the fumonisin-producing Fusarium verticillioides. Journal of Microbiological Methods 68: 312-317.
Magan, N., Hope, R., Cairns, V. and Aldred, D., 2003. Post-harvest fungal ecology: impact of fungal growth and mycotoxin accumulation in stored grain. European Journal of Plant Pathology 109: 723-730.

Munkvold, G.P., 2003. Cultural and genetic approaches to managing mycotoxins in maize. Annual Review of Phytopathology 41: 99-106.

Mulè, G., Susca, A., Stea, G. and Moretti, A., 2004. A species-specific PCR assay based on the calmodulin partial gene for identification of Fusarium verticillioides, F. proliferatum and F. subglutinans. European Journal of Plant Pathology 110: 495-502.

Mishra, P.K., Fox, R.T.V. and Culham, A., 2003. Development of a PCR-based assay for rapid and reliable identification of pathogenic Fusarium. FEMS Microbiology Letters 218: 329-332.

Nicholson, P., Simpson, D.R., Weston, G., Rezanoor, H.N., Lees, A.K., Parry, D.W. and Joyce, D., 1998. Detection and quantification of Fusarium culmorum and Fusarium graminearum in cereals using PCR assays. Physiological and Molecular Plant Pathology 53: 17-37.

O’Donnell, K., Kistler, H.C., Cigelnik, E. and Ploetz, R.C., 1998. Multiple evolutionary origins of the fungus causing Panama disease of banana: concordant evidence from nuclear and mitochondrial gene genealogies. Proceedings of the National Academy of Sciences of the USA 95: 2044-2049.

O’Donnell, K., Ward, T.J., Geiser, D.M., Kistler, H.C. and Aoki, T., 2004. Genealogical concordance between the mating type locus and seven other nuclear genes supports formal recognition of nine phylogenetically distinct species within the Fusarium graminearum clade. Fungal Genetics and Biology 41: 600-623.

Presello, D.A., Botta, G., Iglesias, J. and Eyherabide, G.H., 2008. Effect of disease severity on yield and grain fumonisin concentration of maize hybrids inoculated with Fusarium verticillioides. Crop Protection 27: 572-576.

Qin, Z.H., Ren, X., Jiang, K., Wu, X.F., Yang, Z.H. and Wang XM., 2014. Identification of Fusarium species and F. graminearum species complex associated with maize ear rot in China. Acta Phytophylacica Sinica 41: 589-596.

Qu, X.L., Xu, X.D., Dong, H.Y., Wang, L.J., Jiang, Y., Song, Y.C. and Gai, S.J., 2009. Analysis of fungi species diversity on maize kernels. Journal of Maize Sciences 17: 115-117.

Reynoso, M., Chulze, S., Zeller, K., Torres, A. and Leslie, J., 2009. Genetic structure of Fusarium verticillioides populations isolated from maize in Argentina. European Journal of Plant Pathology 123: 207-215.

Suga, H., Karugia, G.W., Ward, T., Gale, L.R., Tomimura, K., Nakajima, T., Miyasaka, A., Koizumi, S., Kageyama, K. and Myakumachi, M., 2008. Molecular characterization of the Fusarium graminearum species complex in Japan. Phytopathology 98: 159-166.

Wang, Q.M., Wang, J.S., Yu, F.G., Zhu, X., Zaleta-Rivera, K. and Du L., 2006. Mycotoxin fumonisins: health impacts and biosynthetic mechanism. Progress in Natural Science 16: 7-15.

Wang, Y., Dong, Y.J., Yue, H., Li, Z.M., Chen, Y.B., Wang, Y.T., Deng, L.G. and Zhao, S.C., 2016. Investigation and analysis on mycotoxins contamination of maize in Shandong Province. Science and Technology of Cereals Oils Foods 24: 69-73.

Xu, J., Jiang, Y., Qin, P.W., Liu, K.J., Hu, L., Sun, H.J. and Xu, X.D., 2019. Test for ear rot resistance against Fusarium verticillioides and Fusarium graminearum in imported maize germplasm. Journal of Plant Genetic Resources 20: 20-25. 
Xu, X.D. and Liu, Z.H., 2009. A color atlas of maize diseases and pests. China Agricultural Science and Technology Press, Beijing, China P.R. Zhang, H., Van der Lee, T.A.J., Waalwijk, C., Chen, W.Q., Xu, J., Xu, J.S., Zhang, Y. and Feng, J., 2012. Population analysis of Fusarium graminearum species complex from wheat in China show a shift to more aggressive isolates. PloS ONE 7: e31722.
Zhang, H., Zhang, Z., Van der Lee, T., Xu, J., Xu, J.S., Yang, L., Yu, D., Waalwijk, C. and Feng, J., 2010. Population genetic analyses of Fusarium asiaticum populations from barley suggest a recent shift favoring 3ADON producers in southern China. Phytopathology 100: 328-336.

Zou, C.J., Cui, L.N., Zhang, Z.Y., Zhang, X.F., Li, R.J., Chen, G. and Li, X., 2017. Evaluation of maize inbred lines for resistance to Fusarium verticillioides ear rot. Southwest China. Journal of Agricultural Sciences 30: 1346-1349. 
